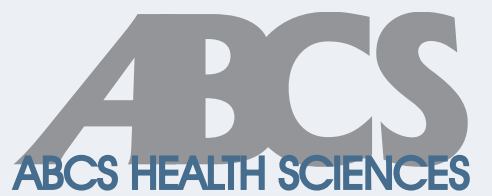

How to cite this article: Santos et al. COVID-19 and the incidence of neglected tropical diseases: reflections from pandemic times. ABCS Health Sci. 2021;46:e021102. https://doi.org/10.7322/abcshs.2021009.1732

Corresponding author: José Bruno Nunes Ferreira Silva - Universidade Federal do Tocantins - Avenida NS 15, ALCNO 14, Bala I, 109 Norte - Plano Diretor Norte - CEP: 77001-090 - Palmas (TO), Brasil -

E-mail: nunes.brj@mail.uft.edu.br

Declaration of interests: nothing to declare

This is an open access article distributed under the terms of the Creative Commons Attribution License (C) 2021 Silva et al

\title{
COVID-19 and the incidence of neglected tropical diseases: reflections from pandemic times
}

\author{
Gessi Carvalho de Araújo Santos ${ }^{1}$ Sandra Maria Botelho Mariano, \\ José Bruno Nunes Ferreira Silva ${ }^{1}$ \\ ${ }^{1}$ Curso de Medicina, Universidade Federal do Tocantins (UFT) - Palmas (TO), Brazil.
}

As of January 6th, 2021, Brazil reported the highest number of coronavirus disease (COVID-19)-related deaths in Latin America. Despite mitigating social distancing, quarantine, and isolation, COVID-19 continues to spread across the country and worldwide. This scenario could overload the Brazilian National Health System in tropical regions where populations are frequently affected by emerging or reemerging arboviral or parasitic diseases. Therefore, in addition to the threat posed by COVID-19, turning into a new neglected tropical disease (NTD) in low- and middle-income countries, increased focus of health systems on mitigating this viral threat could negatively affect existing NTD-related programs ${ }^{1}$.

Herein, we present the epidemiological data of three NTDs in the Tocantins state, located in a high-risk area for NTD-related deaths in the Brazilian Legal Amazon. Data regarding probable cases of Dengue virus (DENV), cutaneous leishmaniasis (CL), and leprosy reported during the first seven months of the last years (2015-2020) were obtained from the Secretary of Health of the Tocantins. They were compared with the data of confirmed COVID-19 cases $^{2}$.

Fewer probable cases of DENV, involving symptoms resembling those of COVID-19 (fever, headache, muscle pain, weariness, and skin rash), were reported in 2020 than in the previous years (2015-2019). Contrastingly, the incidence rates of CL or leprosy in the first three months of 2020 were equal to or higher than those reported in the corresponding months of previous years (Figure 1A-C). We also observed that the number of CL and DENV cases significantly increased during 2018-2019, while the number of leprosy cases steadily increased during 2015-2019 (Figure 1D). However, at the onset of the COVID-19 outbreak in the Tocantins state, epidemiological data showed an abrupt change for each NTD. In March 2020, the number of NTD cases decreased while COVID-19 exceeded the monthly mean value observed in previous years (2015-2019). Interestingly, no CL case was reported in July 2020 (Figure 1A-C). Additionally, the total number of cases for DENV and CL was similar to that reported in 2018. However, each NTD presented a lower number of cases than that noted in 2016 (Figure 1D). These implications were particularly robust for diseases that require long-term clinical monitoring and treatment, such as leprosy, which also has a high endemicity in the state ${ }^{3}$.

Reflecting on the presented epidemiological data, we report that the diagnosis of both arboviral and parasitic diseases was affected by the pandemic. Several hypotheses suggest possible explanations, which should be addressed, for the reduction of NTD incidence during this period. First, primary health care focused on NTDs should be reduced or interrupted during the collapse of a health professional's activity due to an overwhelming number of COVID-19 cases. The social restrictions on movement and risk of contact with the severe acute respiratory syndrome coronavirus 2 in health care 
A

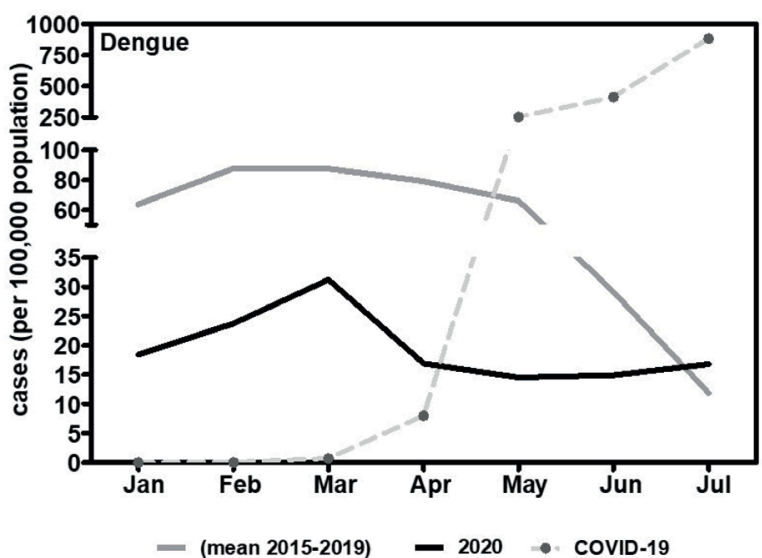

C

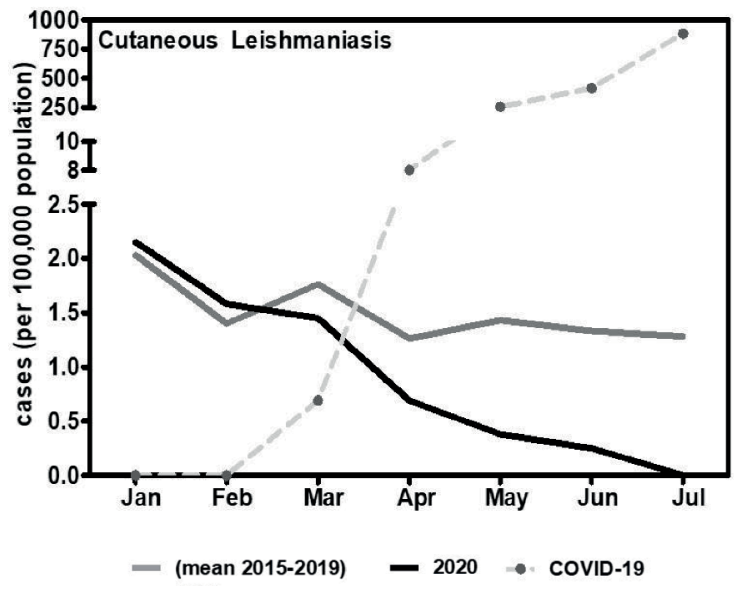

B

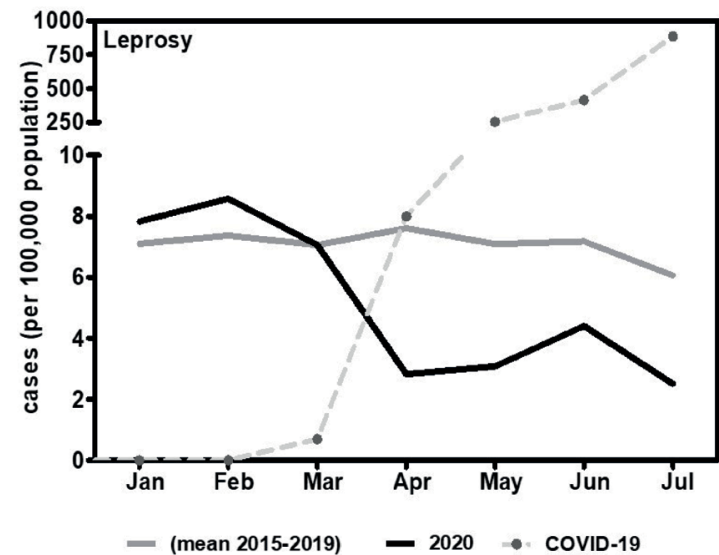

D

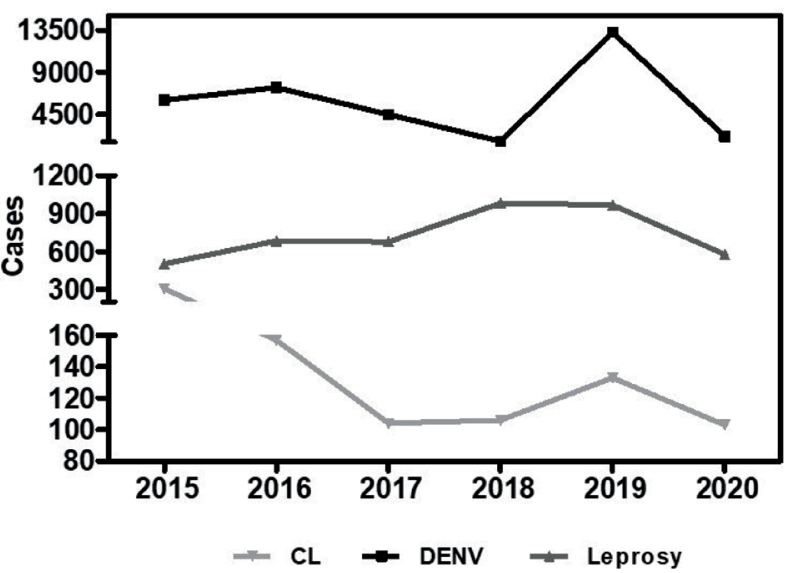

Figure 1: Incidence of cutaneous leishmaniasis (CL), dengue (DENV), and leprosy in the state of Tocantins, Brazil. (A-C) The incidence of neglected tropical diseases (NTDs) was calculated as the sum of new cases identified during 2015-2020 divided by the size of the population in each month. The number of cases identified during 2015-2019 is expressed as the mean value. The number of DENV cases was lower in all months of 2020 than in the corresponding months of previous years. CL and leprosy incidence between January and March 2020 was similar to or greater than that seen in the corresponding months of previous years (2015-2019). In March 2020, there was a marked reduction in the number of probable cases for NTDs, coinciding with the increase in COVID-19-positive cases. (D) In 2020, the total number of cases in the first seven months reduced to that of the baseline value in 2016. Data were performed with GraphPad Prism 5 Statistical Software Package (GraphPad Software, La Jolla, CA, USA).

units may have negatively affected the incidence of NTDs by increasing the stigma, prejudice, and discrimination faced by infected individuals, particularly those with CL or leprosy; therefore, further excluding them. The severity of diseases may also impact the number of reported cases, as most individuals commonly access healthcare services only when chronic symptoms become more evident. This harmful underreporting could result in negative consequences, primarily concerning access to NTD treatment through health services.

Therefore, efforts should be made to improve the prevention and diagnosis of NTDs. Technological innovations, such as geosocial applications, phone-based technologies, or short message service
(SMS)-based tracking systems, must be implemented as adjuvants to identify and manage people with NTDs ${ }^{4}$. Additionally, telehealth could be an alternative to face-to-face patient visits in regions related to new infectious disease outbreaks ${ }^{5}$. We also highlight the importance of performing molecular laboratory tests to robustly identify the viral agent and avoid dangerous consequences of incorrect diagnosis in co-epidemics. Finally, we encourage health services to provide new strategies for the identification and monitoring of possible NTD cases during a pandemic through appropriate case management and highly efficient interventions, which should be important not only for control and prevention but also for potentially ameliorate NTDs treatment. 


\section{REFERENCES}

1. Hotez PJ, Bottazzi ME, Singh SK, Brindley PJ, Kamhawi S. Will COVID-19 become the next neglected tropical disease? PLoS Negl Trop Dis. 2020;14(4):e0008271. https://doi.org/10.1371/journal.pntd.0008271

2. Governo do Estado de Tocantins. Secretaria de Estado da Saúde. Vigilância em Saúde. Centro de Informações e Decisões Estratégicas em Saúde. [Cited Feb 03, 2021] Available from: http://integra.saude.to.gov.br/

3. Ferreira AF, Souza EA, Lima MS, García GSM, Corona F, Andrade ESN, et al. Mortalidade por hanseníase em contextos de alta endemicidade: análise espaço-temporal integrada no Brasil. Rev Panam Salud Publica. 2019;43:e87.

4. Souza DK, Picado A, Biéler S, Nogaro S, Ndung'u JM. Diagnosis of neglected tropical diseases during and after the COVID-19 pandemic. PLoS Negl Trop Dis. 2020;14(8):e0008587. https://doi.org/10.1371/journal.pntd.0008587

5. Caetano R, Silva AB, Guedes ACCM, Paiva CCN, Ribeiro GR, Santos DL, et al. Challenges and opportunities for telehealth during the COVID-19 pandemic: ideas on spaces and initiatives in the Brazilian context. Cad Saude Publica 2020;36(5):e00088920. https://doi.org/10.1590/0102-311×00088920 